\title{
Dealing with dementia
}

Written by: Balázs Gyimesi, OECD Observer

Last update: 28 January 2020

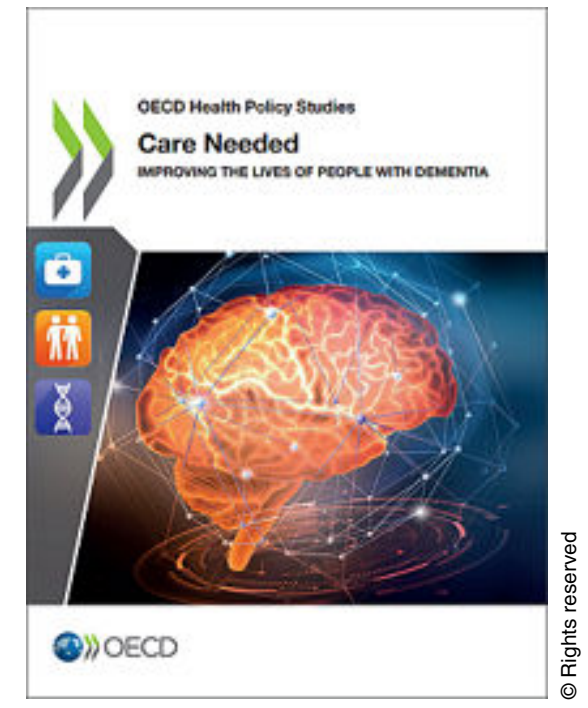

Dealing with dementia I Dealing with dementia - cover of Care needed - Improving the lives of people with dementia

In her Oscar-winning performance as the main character of the 2014 film Still Alice, actress Julianne Moore played a linguistics professor diagnosed with early-onset familial Alzheimer's disease, a rare form of dementia. It was a reminder of the struggle that is affecting the everyday life of a growing number of people worldwide.

In 2017, 19 million people were living with dementia in OECD countries, and by 2050, it will reach an estimated 41 million people, according to Care Needed: Improving the Lives of People with Dementia. Though Ms Moore's character was relatively young, the ageing population of many OECD countries is widely seen as a key factor contributing to the growing prevalence of the disease.

Despite the lack of a cure, there is a range of services available that can improve the health and quality of life of people living with dementia. The trouble is, many people can live with the disease without realising it. Fewer than $40 \%$ of countries are able to estimate diagnosis rates nationally, and in most countries, nonspecialist primary care serves as the first point of contact for people with memory problems. The quality of care for people with dementia is often poor, with most 
care facilities not being designed appropriately, even though $70 \%$ of nursing home residents have some form of cognitive impairment.

Fortunately, governments have started to realise the scope of the challenge ahead. To date, 25 OECD countries have set up specialist centres called "memory clinics" to help with diagnosis. Over $90 \%$ of OECD countries have developed dementia-friendly community initiatives to reduce stigma and improve the communities' response to people living with the disease. But beyond formal care, policymakers should not forget about family and other informal carers, who represent an estimated $40-75 \%$ of all costs of dementia care through the likes of unpaid labour, forgoing work, and the out-of-pocket costs that informal carers spend on their loved ones. Furthermore, the emotional strain of caring for someone with memory loss can be a burden and lead to burnout, depression, anxiety and other health issues. Those caring for people living with dementia need care and attention too.

@OOECD Observer No 314, Q2 2018

\section{References}

OECD (2018), Care Needed: Improving the Lives of People with Dementia, OECD Health Policy Studies, OECD Publishing, Paris, http://dx.doi.org/https:// doi.org/10.1787/9789264085107-en 